\title{
Tratamiento efectivo de hidrotórax asociado con la diálisis peritoneal en un niño: reporte de un caso
}

\author{
Cahyani Gita Ambarsaria Evita Karianni Bermanshah ${ }^{a} \quad$ Muhammad Arza Putrab $^{\text {b }}$ \\ Farhan Haidar Fazlur Rahman ${ }^{a}$ Sudung Oloan Pardede ${ }^{a}$ \\ ${ }^{a}$ Departamento de Salud Infantil, Facultad de Medicina de la Universidad de Indonesia, Hospital Cipto Mangunkusumo, \\ Jakarta Pusat, Indonesia; \\ ${ }^{\text {b}}$ Departamento de Cirugía, Facultad de Medicina de la Universidad de Indonesia, Hospital Cipto Mangunkusumo, \\ Jakarta Pusat, Indonesia
}

\section{Palabras clave}

Enfermedad renal en fase terminal · Diálisis peritoneal .

Derrame pleural · Pleurodesis

\section{Resumen}

La diálisis peritoneal (DP) ofrece muchas ventajas, entre ellas una mejor calidad de vida para niños con enfermedad renal en fase terminal; sin embargo, el procedimiento está asociado con varias complicaciones, incluyendo filtraciones pleuroperitoneales. En este trabajo reportamos un caso inusual de hidrotórax causado por el uso prolongado de DP en un niño, complicado con neumonía. Un niño varón de 9 años que había recibido DP ambulatoria de manera continua (DPAC) por 22 meses presentó disnea, hinchazón e incremento de peso corporal. El drenaje del tórax produjo $500 \mathrm{~mL}$ de fluido trasudativo. La peritoneografía mediante tomografía computada reveló un incremento del flujo del peritoneo a la cavidad pleural. Se suspendió la DP y se inició la aplicación de hemodiálisis (HD). Se practicó cirugía toracoscópica asistida por video; sin embargo, luego de que el paciente sufrió neumonía durante la hospitalización se observaron adherencias pleurales con apariencia septada. Como resultado, fue difícil identificar una fístula pleuroperitoneal (FPP). El derrame pleural derecho se resolvió luego de la pleurodesis empleando bleomicina. Se realizó DH regular por 10 semanas y posteriormente se reinició la DP. No hubo recurrencia del hidrotórax durante el seguimiento a largo plazo. Sospechamos que el mecanismo subyacente del hidrotórax en nuestro paciente se asoció con una FPP resultante de un defecto congénito en el diafragma o a un defecto adquirido, que produjo la filtración del dializado. Nuestro caso demuestra que un cambio temporal de la DP a la HD, acompañado por pleurodesis, puede ayudar a resolver el hidrotórax que se presenta como complicación del uso prolongado de la DP.

(c) 2020 El (los) autor(es)

Publicado por S. Karger AG, Basilea

\section{Introducción}

El hidrotórax secundario a una fístula pleuroperitoneal (FPP) es una complicación poco frecuente de la diálisis peritoneal (DP) de uso prolongado; su tasa de incidencia en niños es $0.53 \%$. Aunque el mecanismo subyacente aún se desconoce, se especula que puede asociarse con una comunicación pleuroperitoneal $[1,2]$.

information@karger.com www.karger.com/kxn

Karger ${ }^{\prime}=$ BOPEN ACCESS
(C) 2020 The Author(s)

Published by S. Karger GmbH, Freiburg

This is an Open Access article licensed under the Creative Commons Attribution-NonCommercial-4.0 International License (CC BY-NC) (http://www.karger.com/Services/OpenAccessLicense), applicable to the online version of the article only. Usage and distribution for commercial purposes requires written permission.
Presentamos un caso pediátrico de hidrotórax que ocurrió como complicación de DP de uso prolongado; el diagnóstico de hidrotórax se confirmó tras observar un flujo aumentado hacia la cavidad torácica en la peritoneografía con contraste mediante tomografía computada (TC). Fue imposible detectar una FPP durante la cirugía toracoscópica asistida por video (CTAV), porque el caso se complicó con neumonía, y se observaron adherencias pleurales de apariencia septada. 

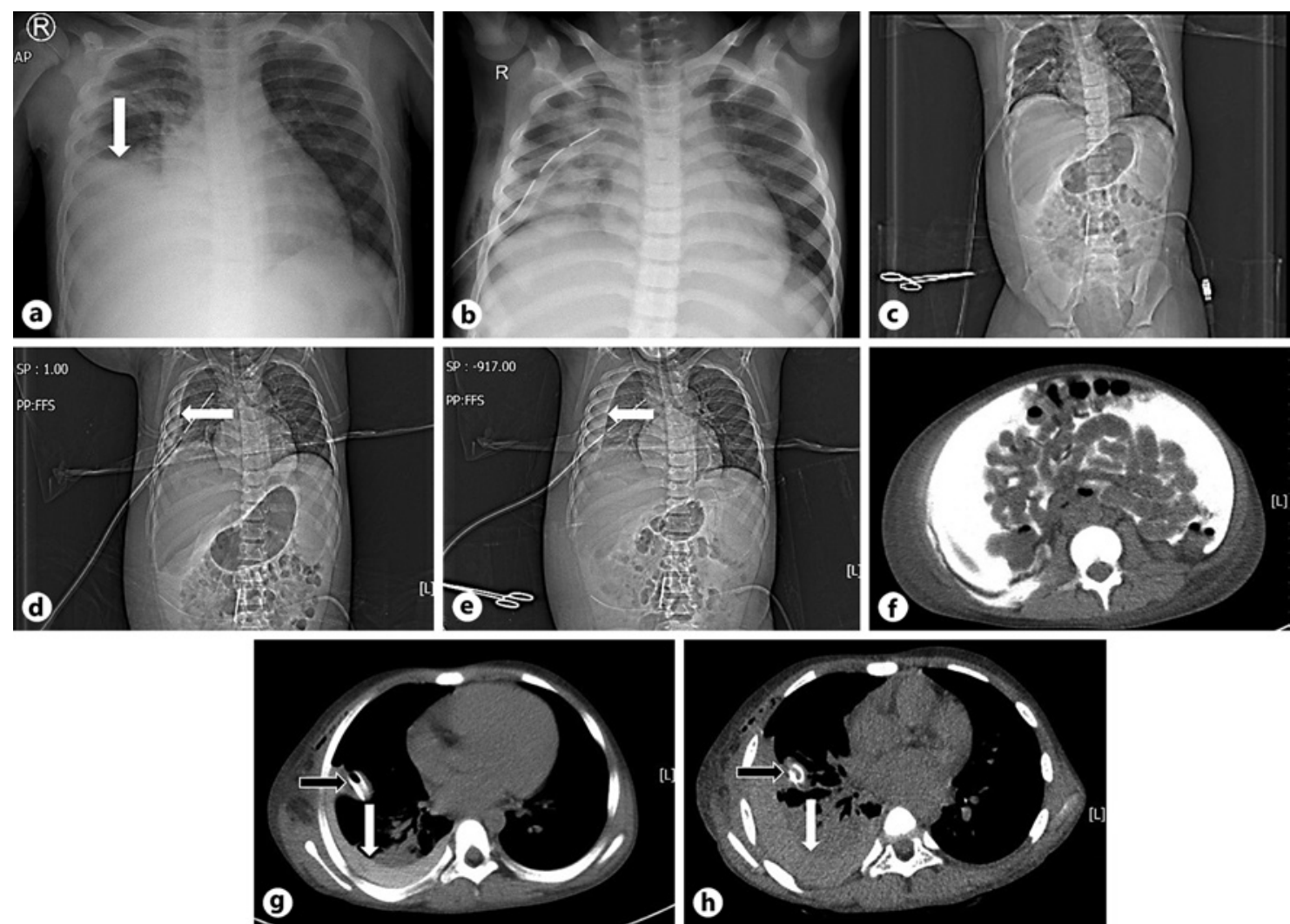

Fig. 1. Serie de imágenes de un paciente masculino, de 9 años, que experimentó hidrotórax mientras recibía DPAC. a La radiografía torácica inicial mostró un derrame pulmonar derecho. b El derrame pleural se resolvió, y se realizó DP con la sonda torácica aún colocada. Obsérvese la presencia de neumonía. c Radiografía del tórax tomada inmediatamente antes de la peritoneografía por TC. La radiografía del tórax muestra la presencia aumentada de fluido en la cavidad pleural derecha al min 30 (d) y al min 180 (e) (flechas blancas). f Una peritoneografía del peritoneo rodeado por solución para diálisis peritoneal conteniendo medio de contraste muestra la presencia aumentada de fluido en la cavidad pleural derecha al min 30 (g) y al min 180 (h) (flechas blancas); las flechas negras indican la posición de la sonda pleural.

Tabla 1. Bioquímica del suero, fluido peritoneal y fluido pleural

\begin{tabular}{lccll}
\hline Espécimen & $\begin{array}{l}\text { Glucosa } \\
(\mathrm{mmol} / \mathrm{L})\end{array}$ & $\begin{array}{l}\mathrm{LDH} \\
(\mu \mathrm{kat} / \mathrm{L})\end{array}$ & $\begin{array}{l}\text { Proteína } \\
(\mathrm{g} / \mathrm{L})\end{array}$ & $\begin{array}{l}\text { Conteo } \\
\text { cellular }(/ \mu \mathrm{L})\end{array}$ \\
\hline Referencia & $3.9-6.1$ & $1.7-3.4$ & $62-85$ & \\
Suero & 5.49 & 12.11 & 54 & \\
Fluido peritoneal & 38.57 & 0.1 & 2 & 2 \\
Fluido pleural & 8.27 & 1.02 & 3 & 26 \\
\hline
\end{tabular}

LDH: lactato deshidrogenasa.

\section{Presentación del caso}

Un niño indonesio de 9 años, con DP ambulatoria continua (DPAC) ingresó en la unidad de emergencia de nuestro centro debido a que presentaba disnea, hinchazón y aumento de peso corporal. No había fiebre, tos ni dolor torácico. Dos años antes, el paciente se diagnosticó con enfermedad renal en fase terminal (ERFT) secundaria a hipoplasia renal bilateral; desde entonces había recibido DPAC consistente en cinco ciclos de intercambio de $1 \mathrm{~L}$ con solución de dextrosa al 1.5\% por 22 meses. El paciente no tenía historial de enfermedad cardiaca, peritonitis, hernia, traumatismo torácico ni abdominal, neumonía, o cirugía torácica ni abdominal, excepto por la inserción del catéter de Tenckhoff. Durante los tres días previos su peso corporal aumentó en $4 \mathrm{~kg}$ (12\%) y experimentó falla en la ultrafiltración, porque aun cuando se infundió $1 \mathrm{~L}$ por ciclo, de la manera usual, el drenaje efluente sólo consistía en unos $0.6 \mathrm{~L}$ por ciclo.

El examen físico mostró una frecuencia respiratoria de 34 respiraciones por minuto, frecuencia cardiaca de 120 latidos por minuto y presión arterial de $147 / 86 \mathrm{mmHg}$. La saturación de oxígeno fue igual a $92 \%$, con una tasa de entrada nasal de oxígeno de $2 \mathrm{~L} /$ min. La auscultación de los pulmones reveló sonidos vesiculares disminuidos en la pared torácica derecha. Los hallazgos cardiacos fueron normales. El análisis gaseoso de la sangre arrojó los siguientes resultados: $\mathrm{pH}$ : 7.467; $\mathrm{pCO}_{2}: 4.51 \mathrm{kPa} ; \mathrm{pO}_{2}: 22.52 \mathrm{kPa}$; bicarbonato: $24.8 \mathrm{mmol} / \mathrm{L}$, y déficit de bases: $2 \mathrm{mmol} / \mathrm{L}$. El nivel de hemoglobina fue $131 \mathrm{~g} / \mathrm{L}$; el nivel de nitrógeno ureico en la sangre fue $7.08 \mathrm{mmol} / \mathrm{L}$, y el nivel de creatinina fue $840.33 \mu \mathrm{mol} / \mathrm{L}$. Una radiografía del tórax reveló la presencia de un derrame pleural derecho e infiltrados pulmonares bilaterales (Fig. 1a). Una sonda pleural drenó $500 \mathrm{~mL}$ de fluido trasudativo. La Tabla 1 mues- 


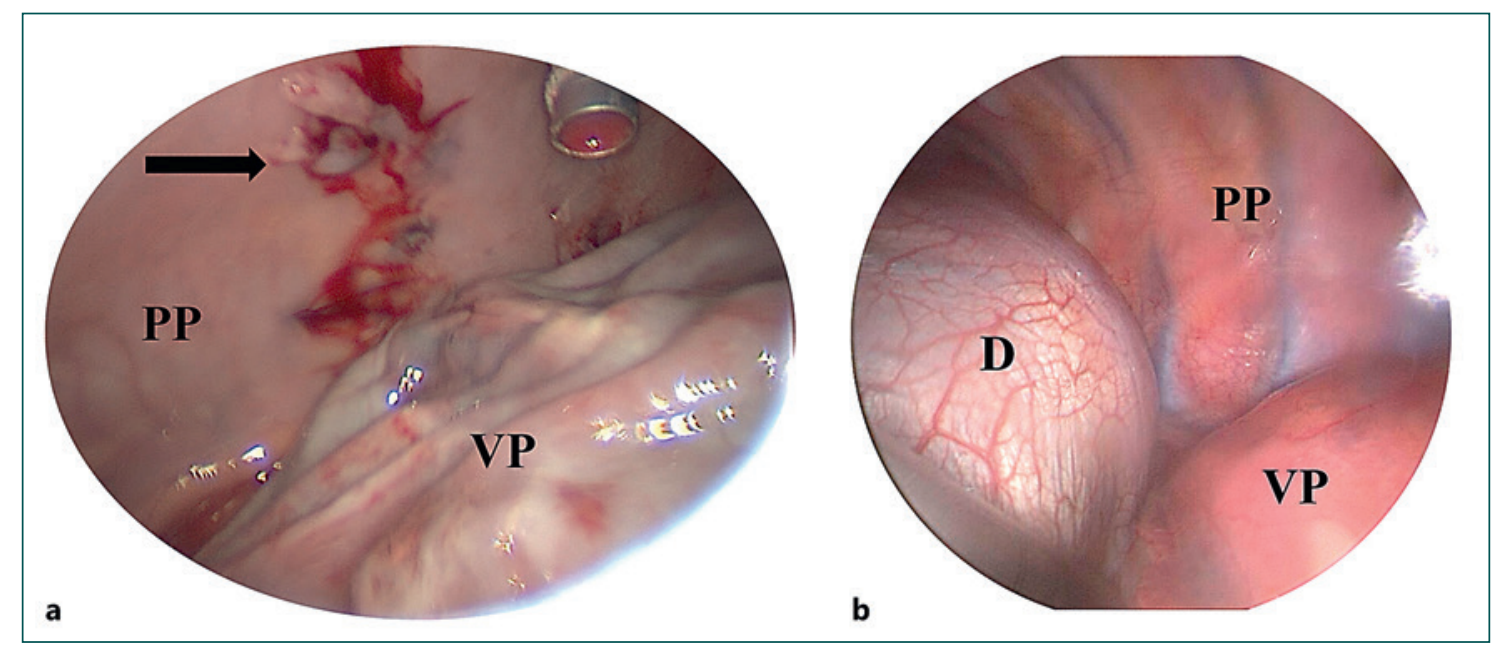

Fig. 2. a La CTAV muestra inflamación en la región luego de la remoción de los septos, antes de la adhesiólisis. b la CTAV no mostró defectos sobre el diafragma, ni se observaron fístulas.

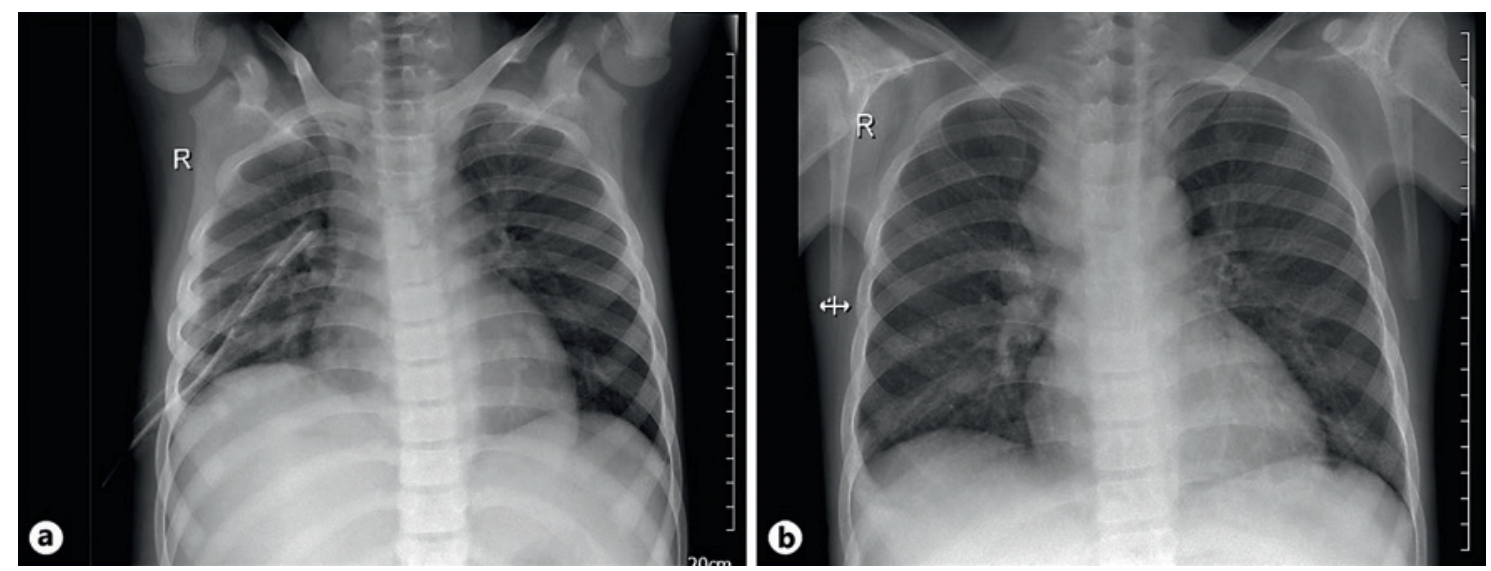

Fig. 3. a Primera radiografía de seguimiento luego de suspender la DP e iniciar la HD mostró una reducción del derrame pleural. b La radiografía de seguimiento a tres años mostró una resolución completa del derrame pleural, sin recurrencias.

tra una comparación de los parámetros del suero, el fluido pleural y el fluido peritoneal.

Tras eliminar completamente el fluido pleural excesivo, se continuó la DP mediante una sonda pleural instalada (Fig. 1b). Se administró cefotaxima intravenosa para tratar la neumonía que ocurrió como complicación adicional. Posteriormente se encontró derrame pleural recurrente, junto con falla en la ultrafiltración. El cultivo del fluido pleural no mostró crecimiento microbiano. Se sospechó la presencia de hidrotórax secundario a FPP, y se suspendió la DP desde el octavo día de hospitalización. En ese momento se inició la aplicación de hemodiálisis (HD) al paciente. Al noveno día se realizó una peritoneografía mediante TC, usando $300 \mathrm{mg} / \mathrm{mL}$ del agente de contraste iohexol diluido en fluido para DP. El examen serial, 30 y 180 min después de administrar el agente de contraste, mostró un exceso de fluido en la cavidad pleural derecha (Fig. 1c-h). Se sospechó la presencia de una FPP posterolateral.

El paciente se sometió a CTAV al vigésimo día de hospitalización; sin embargo, no se detectó fístula alguna en la cavidad torácica derecha. En su lugar, se observaron adherencias entre la pleura parietal y la visceral, con apariencia septada (Fig. 2a y b). Se realizó pleurodesis utilizando $20 \mathrm{~mL}$ de bleomicina para el diafragma derecho. Luego de esto se resolvió el derrame en el pulmón derecho (Fig. 3a), y el paciente recibió HD regular por 10 semanas. Posteriormente, se inició la DP gradualmente hasta alcanzar $1 \mathrm{~L}$ de solución de dializado de dextrosa al 1.5\% con cinco cambios diarios. El seguimiento a tres años mostró una DP normal, sin recurrencia de hidrotórax (Fig. 3b).

\section{Discusión/Conclusión}

Este trabajo describe un caso pediátrico de hidrotórax que apareció como una complicación de DP de uso prolongado. La DP es la modalidad de tratamiento de reemplazo renal recomendada para niños con ERFT. Si bien esta intervención brinda una mejor calidad de vida [3], se ha asociado con complicaciones no-infecciosas, como obstrucción o falla del catéter, filtración, defectos en la pared abdominal, FPP o falla en la ultrafiltración [4]. 
Los síntomas del hidrotórax usualmente involucran dificultad respiratoria, particularmente disnea $[1,2]$ - que se observó en nuestro paciente -, así como sonidos vesiculares disminuidos en la auscultación, y derrame pleural en la radiografía torácica. Sin embargo, aún se desconoce el mecanismo subyacente del hidrotórax secundario a la DP. Se ha postulado que el hidrotórax se asocia con una FPP que se forma como consecuencia de un defecto congénito del diafragma o un defecto adquirido, lo que genera el movimiento del dializado del peritoneo a la cavidad pleural $[1,2]$. Una alteración en el gradiente de presión pleuroperitoneal secundaria a la DP que ocurrió durante un periodo de 21 meses pudo haber disparado la FPP en nuestro paciente [5].

La peritoneografía mediante TC es ventajosa para retratar la cavidad peritoneal y torácica completa, con costos mínimos en comparación con la peritoneografía mediante resonancia magnética [6]. La gammagrafía peritoneal puede realizarse utilizando albúmina macroagregada con tecnecio-99 como agente de contraste [5]. En este caso empleamos iohexol como agente de contraste, que realza el rasgo de imagen característico de la FPP. Mediante la CTAV se detectaron posibles defectos en la pleura y el diafragma, pero no se observó ninguna fístula en la cavidad torácica derecha. En su lugar, adherencias con aspecto septado, presumiblemente secundarias a la neumonía, hicieron difícil identificar la fístula. Aunque el talco ofrece mejores resultados - puesto que puede inhibir la angiogénesis e impedir el derrame pleural recurrente [7] - se utilizó la bleomicina para la pleurodesis en nuestro paciente porque no se disponía de talco. Adicionalmente, la bleomicina es menos tóxica que otros agentes como la yodopovidona [8]. Aunque la bleomicina es más costosa que el talco (796 USD vs. 488 USD), la primera tiene una tasa de éxito de $87.6 \%$ para prevenir la recurrencia del derrame, menor que la del talco, de 90.2\% [9]. Ha habido cinco casos de pleurodesis en nuestro centro durante el periodo 2016-2019, en los que se empleó bleomicina en adultos con neumotórax catamenial $(\mathrm{n}=1)$ y neumotórax espontáneo asociado con metástasis tumoral $(n=4)$ como enfermedades primarias. No se observaron efectos colaterales o recurrencia del neumotórax durante el seguimiento de uno a tres años. Éste es el primer caso de pleurodesis empleando bleomicina en un paciente pediátrico y el primer caso de pleurodesis por sospecha de FPP en un paciente pediátrico con uso prolongado de DP en nuestro centro.

Nuestros hallazgos sugieren que descontinuar la DP puede prevenir la ocurrencia de un derrame en crecimiento. Anteriormente se ha recomendado la HD temporal por 4-16 semanas [10]. En consecuencia, realizamos HD por 10 semanas y posteriormente reiniciamos la DP. El seguimiento a largo plazo no mostró recurrencia de hidrotórax. En conclusión, mostramos que el diagnóstico de FPP por peritoneografía mediante TC utilizando iohexol como contraste, seguido por un cambio temporal de DP a HD, y la pleurodesis empleando bleomicina, constituyen un método potencialmente válido para tratar a un paciente con hidrotórax que se presenta como complicación de la DP de uso prolongado en entornos con recursos limitados.

\section{Agradecimiento}

Agradecemos encarecidamente al profesor Taralan Tambunan, al profesor Partini Pudjiastuti Tri-hono, al Dr. Eka Laksmi Hidayati y al Dr. Henny Adriani Puspitasari por el cuidado al paciente en el Departamento de Salud Infantil. Asimismo, quisiéramos expresar nuestra gratitud a las enfermeras de la unidad pediátrica de diálisis del HCM, Yetti Marlina, Mustaqimah, Dorkasturi Sitompul, Meldahania, Ani Suryani, Emma Meida Ekawati y Resti Fitria Pramandani por realizar tan cuidadosamente las sesiones de hemodiálisis. También quisiéramos agradecer a la Dra. Elysabeth Muliawan por sus servicios de edición de la versión en inglés de este manuscrito, y a Enago (http://www.enago.com) por la cuidadosa lectura y edición de este manuscrito.

\section{Declaración de ética}

La investigación se realizó de manera ética, de conformidad con la Declaración de Helsinki de la Asociación Médica Mundial. Se obtuvo consentimiento informado por escrito del tutor legal para la publicación de este reporte de caso y de cualesquier imágenes. Una copia del consentimiento escrito está disponible para revisión por el editor de esta revista.

\section{Conflictos de interés}

Los autores no tienen conflictos de interés que declarar.

\section{Fuentes de financiamiento}

Ninguna.

\section{Contribuciones de los autores}

CGA y FHFR realizaron la búsqueda en la literatura, así como la recolección, el análisis y la interpretación de los datos, y escribieron el primer borrador del manuscrito. EKB y MAP realizaron la recolección y el análisis de datos, revisaron el manuscrito y aprobaron la versión final. SOP revisó críticamente el manuscrito. Todos los autores leyeron y aprobaron el manuscrito final.

\section{Información sobre licencias}

Cahyani Gita Ambarsari, Evita Karianni Bermanshah, Muhammad Arza Putra, Farhan Haidar Fazlur Rahman, Sudung Oloan Pardede: Tratamiento efectivo de hidrotórax asociado con la diálisis peritoneal en un niño: reporte de un caso. Case Rep Nephrol Dial. 2020;10:18-25. (https:// doi/10.1159/000506119). ${ }^{\circ}$ Este artículo está protegido por la Licencia Internacional Creative Commons de atribución, no-comercial, sin derivados CC BY NC-ND) (http://www.karger.com/Services/OpenAccessLicense). El uso y la distribución para propósitos comerciales, así como cualquier distribución de material modificado, requieren permiso por escrito.

\section{Referencias}

Las referencias están disponibles en www.karger.com/Article/Fulltext/ 000513579 . 